\title{
Sustentabilidade na Produção da Agricultura Familiar: o Projeto Rede Viva Charqueadas
}

\author{
Sustainability in the Production of Family Agriculture: the Project Rede Viva \\ Charqueadas
}

\author{
Sostenibilidad en la Producción de Agricultura Familiar: el Proyecto Red Viva \\ Charqueadas
}

\author{
Daiane Lindner Nascimento Bittencourt ${ }^{1}$ \\ Patrícia Mendes Calixto ${ }^{2}$
}

\begin{abstract}
RESUMO: Neste artigo analisamos os resultados da implantação das diretrizes do projeto Rede Viva Charqueadas, concebido através de um convênio firmado entre o município de Charqueadas/RS com a Petrobras Fome Zero: Desenvolvimento com Cidadania. $O$ objetivo deste foi apoiar pequenos produtores rurais do Município de Charqueadas, identificando a matriz produtiva e fortalecendo o desenvolvimento econômico rural com base em técnicas sustentáveis e agroecológicas de produção. O Rede Viva foi criado para incentivar novas tecnologias com potencial de inclusão, focado na organização de um programa de Economia Solidária. Neste artigo apresentamos o Diagnóstico Rápido Participativo (DRP) no qual a realidade de cada família foi analisada e, a partir desses dados, avaliamos a execução das ações sustentáveis dentro da agricultura familiar.
\end{abstract}

PALAVRAS-CHAVE: Sustentabilidade. Agroecologia. Economia Solidária. Agricultura familiar.

ABSTRACT: In this article we analyze the results of the implementation of the Rede Viva Charqueadas project guidelines, conceived through an agreement signed between the of Charqueadas city / RS and Petrobras Fome Zero: Development with Citizenship. The objective of this project was to support small farmers in the of Charqueadas city, identifying the productive matrix and strengthening rural economic development based on sustainable agroecological production techniques. Rede Viva was created to encourage new technologies with potential for inclusion, focused on the organization of a Solidarity Economy program. In this article we present the Rapid Participatory Diagnosis (RPD) in which the reality of each family was analyzed and, from these data, we evaluate the execution of the sustainable actions within the family agriculture.

KEYWORDS: Sustainability. Agroecology. Solidarity Economy. Family farming.

RESUMEN: En este artículo analizamos los resultados de la implantación de las directrices del proyecto "Rede Viva Charqueadas", concebido a través de un convenio firmado entre el municipio de Charqueadas / RS con Petrobras Hambre Cero: Desarrollo con Ciudadanía. El objetivo de este fue

\footnotetext{
${ }^{1}$ Instituto Federal Sul-rio-grandense. RS 401 Km 18 - Parque de Eventos -CharqueadasRS; CEP: 96745-000; daiane.Inb@hotmail.com.

2 Instituto Federal Sul-rio-grandense. Rua General Balbão, 81, Charqueadas, CEP: 96745-000/RS; patriciacalixto@ifsul.edu.br.
} 
apoyar a pequeños productores rurales del Municipio de Charqueadas, identificando la matriz productiva y fortaleciendo el desarrollo económico rural con base en técnicas sostenibles y agroecológicas de producción. La Rede Viva fue creada para incentivar nuevas tecnologías con potencial de inclusión, enfocadas en la organización de un programa de Economía Solidaria. En este artículo presentamos el Diagnóstico Rápido Participativo (DRP) en el cual la realidad de cada familia fue analizada y, a partir de esos datos, evaluamos la ejecución de las acciones sostenibles dentro de la agricultura familiar.

PALABRAS CLAVES: Sostenibilidad. Agroecología. Economía Solidaria. Agricultura familiar.

\section{APRESENTANDO O TEMA}

A introdução de processos de sustentabilidade nas práticas agrícolas dos pequenos produtores traz luz a esse grupo de trabalhadores que contribui fortemente para a produção de alimentos do país. O projeto denominado Rede Viva Charqueadas estabelece diretrizes e objetivos que dão visibilidade a esses produtores vinculados à agroecologia no município de Charqueadas. Neste artigo, apresentamos as principais ações relacionadas à esse projeto. Para tanto, trouxemos os conceitos de sustentabilidade, sujeito ecológico, economia solidária e agricultura familiar para elucidar as escolhas, entender os resultados e compreender o planejamento das ações para o futuro.

O desafio do mundo contemporâneo, como se sabe, é produzir alimentos, fibras e energia para atender o contingente populacional atual e crescente. $O$ Brasil está entre as nações com forte potencial para atender uma parte dessa demanda já que apresenta disponibilidade de terras agriculturáveis e tecnologia para melhorar o rendimento dos cultivos.

A agricultura familiar, segundo a Organização das Nações Unidas (PORTAL BRASIL, 2014) é responsável por atender basicamente as populações urbanas, o que garante a segurança alimentar e nutricional. Além disso, compõe os $84 \%$ de todas as unidades produtivas do país, apresentando complexidade em sua estrutura, o que desafia os pesquisadores do setor.

Neste cenário nasceu o projeto Rede Viva Charqueadas, cuja finalidade é expandir as técnicas da agroecologia, a fim de favorecer os sistemas naturais, ajudando no combate às degradações e aos desequilíbrios ambientais causadas pelo uso inadequado dos bens naturais. Vale destacar que optamos pelo uso do termo "bens naturais" seguindo orientação da pesquisadora Ribeiro (2003), pois este se refere ao pertencimento em oposição ao termo "recurso" cujo uso está relacionado à exploração sem critérios. 
A sustentabilidade como direcionamento é fundamental, pois, como afirma Leff (2002), o equilíbrio ecológico, a preservação da biodiversidade e a qualidade de vida dos seres humanos são fundamentos para a própria economia equilibrada. Sendo assim, a busca de alternativas que possam atender o equilíbrio são alicerces, não apenas para a manutenção do sistema, mas para a garantia da qualidade de vida de todos.

A seguir, abordaremos o universo do projeto, evidenciando o contexto em que aconteceram as propostas para o seu desenvolvimento, isto é, no município de Charqueadas/RS, dentro do assentamento Trinta de Maio, composto por famílias oriundas do Movimento dos Trabalhadores Rurais Sem Terra (MST).

Como veremos, a proposta valoriza o desenvolvimento de novas tecnologias com potencial de inclusão. Buscou-se, inicialmente, identificar as demandas locais, focando o aproveitamento das potencialidades endógenas. Em seguida, organizaram-se grupos como estratégia para efetivação de um programa de economia solidária, baseado nas políticas públicas. Por fim, analisaram-se os critérios de sustentabilidade e avaliaram-se as alternativas propostas para reverter o quadro de uso inadequado dos bens naturais. Ainda apresentou-se a análise dos relatos de alguns dos produtores envolvidos nesse processo.

Sobre o referencial teórico baseamo-nos não apenas, mas especialmente, em Boff (2000a, 2000b, 2006a, 2006b, 2011) para ressaltar a importância do cuidado com a terra, pois, segundo o autor, precisamos todos passar por uma alfabetização ecológica e rever nossos hábitos de consumo. O sentido de alfabetização ecológica orienta para a qualidade de vida, para que a sociedade possa ser sustentável e protetora.

Em relação à diversidade do planeta, espera-se que a sociedade possa gerir suas práticas baseada no respeito a todo sistema global, sem agressões, degradações, sem ameaças. Reportamo-nos à necessária noção de cidadania planetária de Gadotti para entender essa questão:

A noção de cidadania planetária sustenta-se na visão unificadora do planeta e de uma sociedade mundial. Ela se manifesta em diferentes expressões: "nossa humanidade comum", "nosso futuro comum", "nossa pátria comum". Cidadania planetária é uma expressão adotada para expressar um conjunto de princípios, valores, atitudes e comportamentos que demonstra uma nova percepção da Terra. Trata-se de um ponto de referência ético indissociável da civilização planetária (GADOTTI, 2009, p. 2).

Desta maneira, considerando a conjuntura atual na qual a agricultura está organizada no país, ou seja, capitalista, voltada ao lucro e à indústria, não há dúvida sobre a importância do investimento em ações voltadas à agricultura familiar baseada na noção de cidadania planetária. 
Como se sabe, a agricultura é uma atividade que causa impactos ambientais (ASSAD; ALMEIDA, 2004), decorrentes da substituição de uma vegetação naturalmente adaptada por outra que exige a contenção do processo de sucessão natural, visando ganhos econômicos. Neste cenário, o desafio consiste em buscar sistemas de produção agrícola adaptados ao ambiente de tal forma que seja mínima a dependência de insumos externos e de bens naturais não renováveis.

No período pós-guerra as dificuldades de manutenção do padrão produtivo foram crescentes, bem como as desigualdades socioeconômicas, o desmatamento e a degradação de solos, resultado da Revolução Verde, cuja postura visou plantios com alto rendimento sem preocupação com o uso da terra. Portanto, os reflexos dessa postura mediante o uso destemido dos bens naturais resultaram no declínio da qualidade de vida, tornando-se um problema ambiental, social, político e econômico. Para Altieri (1998), só uma compreensão mais profunda dos sistemas agrícolas pode levar a medidas coerentes com uma agricultura realmente sustentável.

\section{O UNIVERSO DO PROJETO}

O município de Charqueadas foi emancipado de São Jerônimo no ano de 1982, e está situado à margem direita do Rio Jacuí, pertencendo à área metropolitana da capital do estado. Segundo o Instituto Brasileiro de Geografia e Estatística (IBGE, 2012) tem aproximadamente 36.130 habitantes e seu desenvolvimento econômico está relacionado à área metal/mecânica. Entretanto, a partir dos anos 1990 o setor agropecuário começou a apresentar desenvolvimento gradativo.

É neste ambiente onde está o Assentamento Trinta de Maio cuja organização teve início no início dos anos 1990 com famílias oriundas da Região das Missões e Alto Uruguai do Rio Grande do Sul. Em julho de 1991 inaugurou-se a Cooperativa de Produção Agropecuária dos Assentados de Charqueadas (COPAC). Segundo Teixeira (2008, p. 37), "[...] a própria organização do grupo foi pensada de maneira a facilitar a convivência social e o desenvolvimento de valores humanistas e solidários [...]", cenário apropriado para as atividades propostas pelo "Rede Viva Charqueadas" criado em parceria com o Programa Petrobrás Fome Zero: Desenvolvimento com Cidadania.

Nesta perspectiva, amparou-se na Lei Orgânica do município que prevê o desenvolvimento econômico a partir da melhoria da qualidade de vida da população, bem como orienta sobre o estímulo à permanência do homem no campo, considerando o desenvolvimento social e econômico sustentável. O grande desafio foi implantar um projeto 
que busca tais caminhos através do fomento para a produção agropecuária, da organização do abastecimento alimentar e do estímulo ao melhor aproveitamento da terra.

Avaliando o potencial produtivo do município, identificou-se que a agricultura local necessitava fortalecimento, pois a agricultura familiar já era uma realidade, mas precisava solidificar-se com diversificação da linha produtiva. O Rede Viva Charqueadas atuou baseado nos critérios de sustentabilidade, ajudando os pequenos agricultores a identificar sua matriz produtiva.

O Rede Viva Charqueadas conta com uma equipe multidisciplinar, a qual teve como uma das principais ações analisar o perfil das propriedades rurais, identificar as técnicas utilizadas para o plantio e avaliar os possíveis impactos sobre o meio ambiente. Também foram analisadas as propriedades abrangidas pelo projeto e verificou-se se as mesmas atendiam aos critérios exigidos pelo Sistema de Reforma Agrária como, por exemplo, possuir área de preservação permanente.

Sendo assim, o primeiro passo foi dado para a execução de um projeto que veio com a missão de estimular mudança de atitudes no âmbito das relações sociais de diversos interesses, inclusive a produção sustentável e a adoção de uma matriz tecnológica mais equilibrada do ponto de vista ambiental.

A partir da metodologia de Diagnóstico Rápido Participativo (DRP) foi possível compreender os diversos processos do Desenvolvimento Rural dentro de cada propriedade, ou seja, conhecer a realidade de cada família envolvida pelo projeto, as peculiaridades, fragilidades, potencialidades, oportunidades e deficiências.

Este DRP foi coordenado pela Empresa de Assistência Técnica e Extensão Rural (EMATER/RS), com o apoio do Escritório Regional de Assistência Técnica e Extensão Rural (ESREG), em parceria com Conselho Municipal de Desenvolvimento Rural, Secretaria de Agricultura e Economia Solidária, além das comunidades locais.

O DRP foi ferramenta indispensável para a construção de plano plurianual que foi validado no Fórum Municipal de Desenvolvimento Rural. Conforme destaca Souza (2009, p. 36):

Um processo participativo que proporciona a oportunidade de auto avaliação de si e de sua cultura do grupo a que pertence, capacidade reflexiva sobre os efeitos da vida cotidiana, capacidade de criar e recriar, não somente objetivos materiais, mas também é, fundamentalmente, criar e recriar formas novas de vida e de convivência social. As técnicas de diagnóstico e planejamento participativo devem valorizar, por sua vez, o processo de obtenção de informações. Ė importante que este processo seja, ele mesmo, um fator de obtenção, de formação e de discussão de políticas no seio da comunidade. 
Como se vê, a participação da comunidade favorece a mobilização para a reflexão em torno do tema em questão. Essa metodologia é fundamental para conhecimento da realidade e união dos agentes diversos que podem contribuir direta ou indiretamente com o projeto. Segundo Bassi; Ciotta (2008, p. 10), a escolha desse caminho favoreceu a identificação de algumas potencialidades, dentre elas a produção de arroz: "[...] foi possível identificar grande parte de área alagada em algumas propriedades, representando mais de $18 \%$ do local, o que favoreceu a ideia de produção agroecológica de arroz e hortigranjeiros" (fig.1).

Figura 1 - Fotografia da sistematização da Lavoura de Arroz Agroecológico, com o trator fornecido pelo Projeto Rede Viva

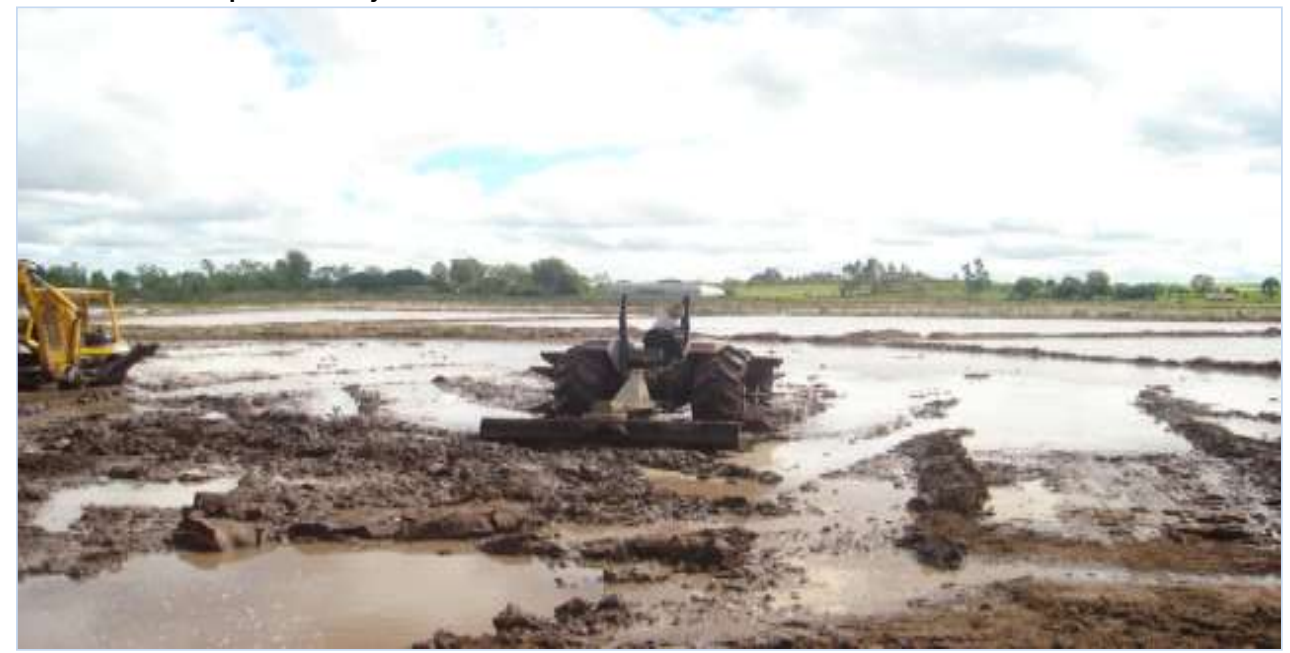

Fonte: Banco de dados do Projeto Rede Viva.

Verificaram-se também na região potencial para o plantio de hortaliças, algumas famílias já possuíam hortas e estavam inseridas no mercado local. Com base na Extensão Rural, observamos a necessidade de ampliar essa demanda de produção e promover critérios de gestão a fim de alcançar objetivos como segurança alimentar e controle biodinâmico, sem uso de agrotóxicos, visando a regeneração do solo:

A opção da Extensão Rural do Rio Grande do Sul foi bastante clara, no sentido de apoiar o processo de transição agroecológica, por entender que a agricultura é um processo de construção social e que, portanto, são as famílias rurais que devem assumir o papel de sujeitos ativos nos processos de desenvolvimento socioeconômico e cultural de suas comunidades (CAPORAL; COSTABEBER, 2001, p. 8).

Foi através desses sujeitos ativos que a equipe identificou a necessidade de criar um Banco de Sementes (fig. 2) com o qual foi possível resgatar sementes crioulas diversas, principalmente de feijão, milho e abóboras, podendo, assim, garantir suas características 
sem alteração genética. A troca dessas sementes acontece em momentos oportunos, isto é, em épocas adequadas para o seu plantio.

Figura 2 - Fotografia do banco de sementes

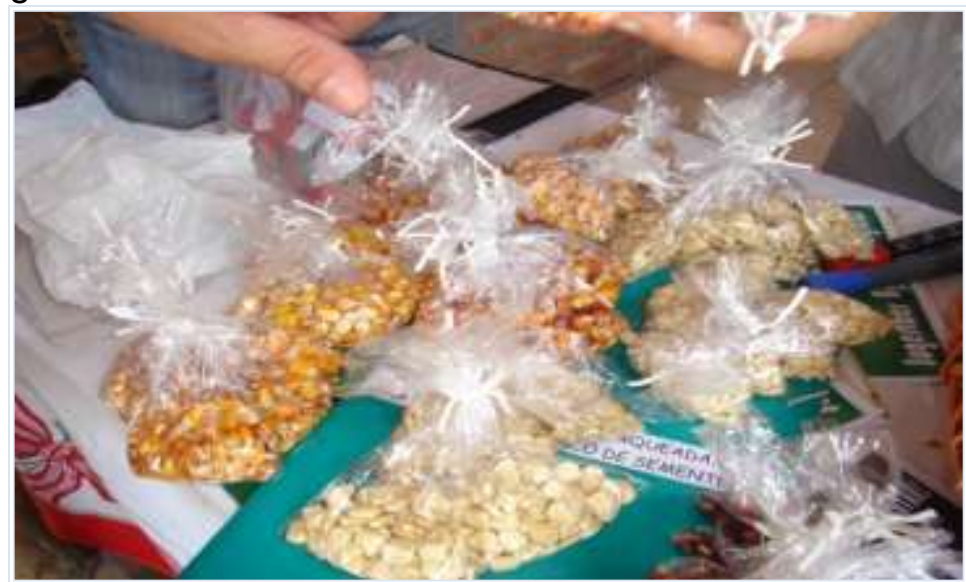

Fonte: Banco de dados do Projeto Rede Viva.

Cabe destacar a importância desta prática para sensibilizar a sociedade quanto ao papel do resgate da biodiversidade e a necessidade da manutenção das sementes em mãos das famílias, com responsabilidade de assegurar a soberania alimentar.

Com o propósito de exercer a prática de produção de sementes junto à comunidade urbana, nasceu a Horta Comunitária (fig. 3), a fim de atender as demandas locais, tornando este espaço produtivo, educativo e terapêutico, local este que se tornou referência em práticas agroecológicas, baseadas na sustentabilidade, observação da natureza, produção limpa, convivência vegetal, onde estudantes e organizações dispunham do espaço para melhor compreender todo o processo. Houve coleta de alimentos e os frutos deste trabalho tiveram como destino os asilos municipais, o hospital local, a Casa da Criança e as creches municipais. O consumo destas hortaliças foi sempre acompanhado de reflexão com relação à forma de cultivo e a identificação dos alimentos e seu papel fundamental no desenvolvimento humano.

O DRP permitiu também observar que alguns apicultores manejavam o sistema sem a estrutura adequada para o processo. Com a possibilidade de expandir a produção, através das visitas da equipe técnica do projeto, entendeu-se que era necessário capacitar os produtores e criar uma associação, além de uma agroindústria. Nela far-se-ia o processamento do mel a fim de certificá-lo e industrializá-lo, abastecendo o mercado local, bem como atender a merenda escolar.

Com a ideia de diversificar a linha de produção de alimentos, estendeu-se o olhar também aos produtores de leite, os quais tinham potencial para atender o mercado. Entretanto, estes estavam predominantemente em áreas periféricas às nucleações urbanas. 
Esses produtores alimentam um sistema de décadas de entrega de leite a domicílio, prática esta não aprovada pela Vigilância Sanitária por uma série de questões que podem comprometer seriamente a saúde do consumidor. Esta prática possui laços de confiança muito fortes e necessitou um trabalho de conscientização do produtor e também do consumidor. Para isso, foi proposta a construção da usina do leite para fortalecer estes laços e garantir um consumo de alimento seguro. Capacitou-se os produtores (fig. 4), ampliando o aprendizado e, através das diferentes formações, exercitando o respeito entre os membros da cadeia produtiva, bem como fortalecendo a capacidade individual em prol do grupo.

Figura 3 - Fotografia de uma horta agroecológica

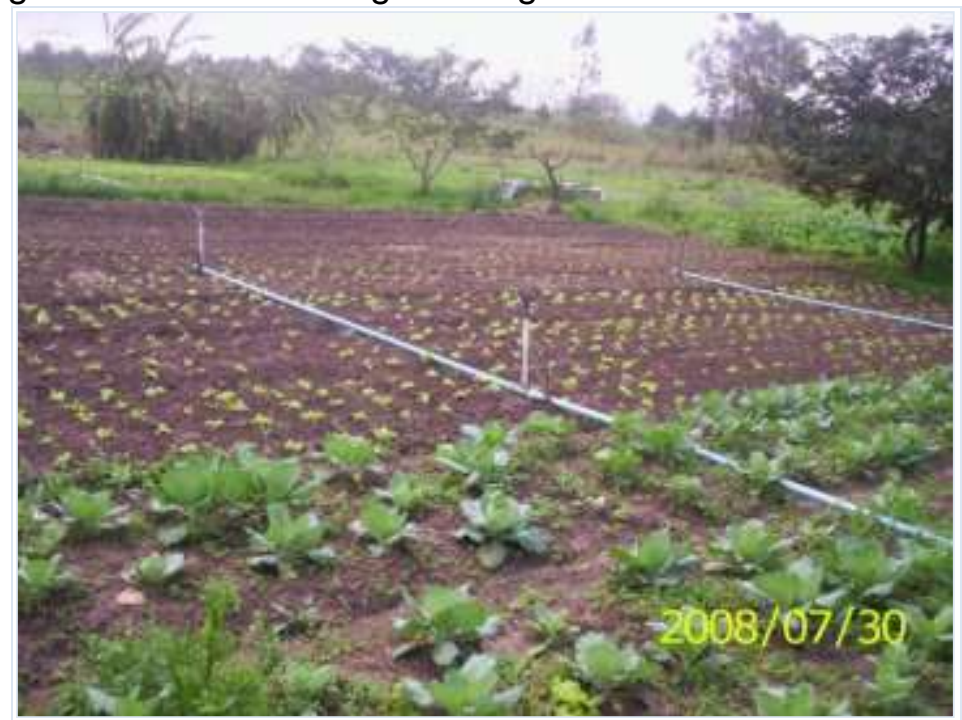

Fonte: Banco de dados do Projeto Rede Viva.

Figura 4 - Capacitação de Produtores de Leite - Subgrupo do Leite

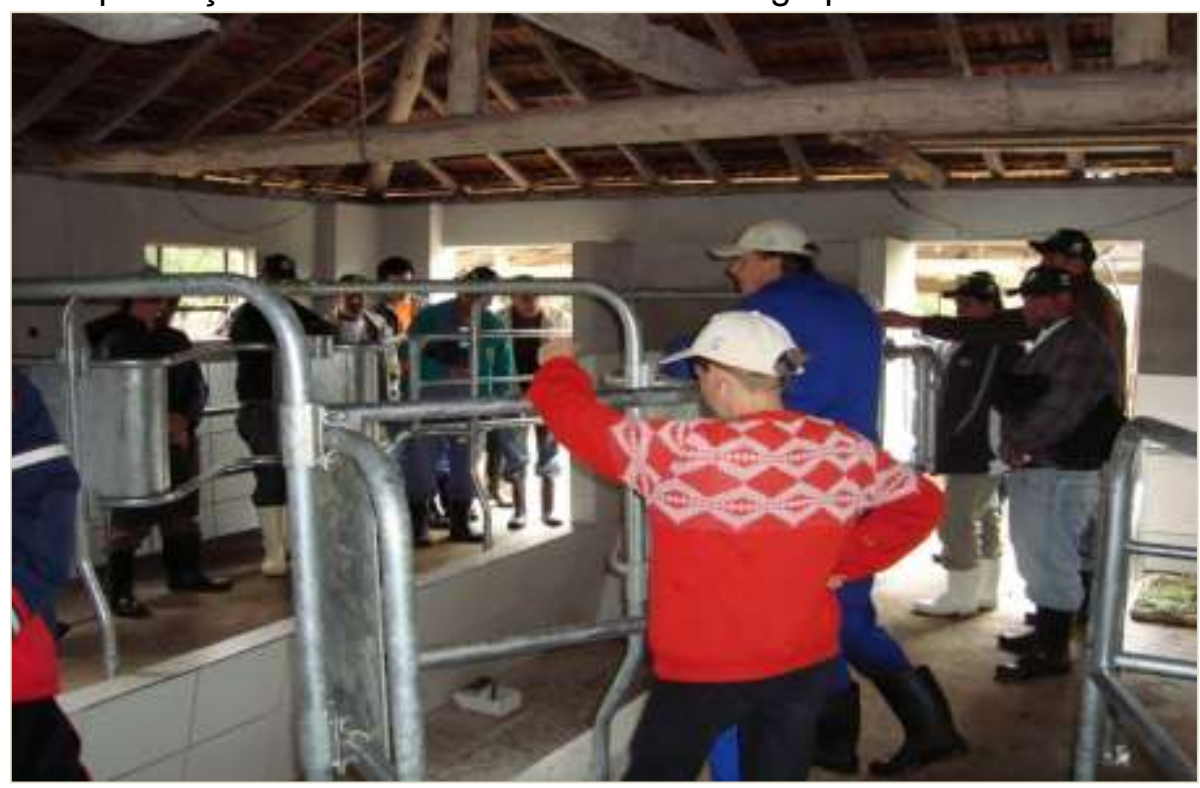

Fonte: Acervo Projeto Rede Viva. 


\title{
TECNOLOGIAS COM POTENCIAL DE INCLUSÃO
}

Entender que a agricultura familiar é uma cadeia de atividades interligadas é uma maneira de tornar as socializações ativas, pois nesse processo as atitudes dos agentes ativos devem estar conectadas. Olhar o mundo como um todo, isto é uma visão ecológica.

\begin{abstract}
O novo paradigma pode ser chamado de uma visão de mundo holística, que concebe o mundo como um todo integrado, e não como uma coleção de partes dissociadas. Pode também ser denominado visão ecológica, se o "termo ecológica" for empregado num sentido muito mais profundo que o usual. A percepção ecológica profunda reconhece a interdependência fundamental de todos os fenômenos, e o fato de que, enquanto indivíduos e sociedades estamos todos encaixados nos processos cíclicos da natureza (e, em última análise, somos dependentes desse processo) (CAPRA, 1996, p. 25).
\end{abstract}

A interligação de todos os envolvidos na sociedade que visa a Agricultura Familiar deve buscar métodos que fortaleçam a capacidade de intervenção da comunidade nas atividades agroecológicas, exercendo o conhecimento singular em prol do resultado coletivo. Favorecer o dinamismo das propriedades envolvidas e garantir a diversificação da linha de produção, para melhorar a qualidade de vida e a segurança alimentar, valorizando a vivência de cada um, mediante exercício do respeito à natureza, são elementos fundamentais:

\begin{abstract}
Nessa perspectiva, a busca de sustentabilidade na agricultura e no desenvolvimento rural implica reconhecer a existência desse saber construído mediante uma lógica indutiva - que vai sendo estabelecido na história dos grupos sociais na medida em que se vê fazer, se escuta para poder dizer, explicar e desenvolver esse conhecimento. Sendo, pois, a agricultura uma atividade humana, ela é uma construção social que, além de ser ambientalmente determinada, está subordinada a determinados condicionantes socioculturais, entre os quais se destaca o conhecimento ou o saber local (CAPORAL; COSTABEBER, 2001, p. 15).
\end{abstract}

Sendo, portanto, uma construção social, foi necessário avaliar o comportamento dos partícipes, para que cada um atue com segurança nos papéis propostos pelos princípios da Economia Solidária. Essa política de uso da terra favorece o fortalecimento da Agricultura Familiar e permite, através do trabalho coletivo, o potencial de inclusão, sem vistas a atender o mercado capitalista, onde todos decidem o que é melhor para o coletivo, sempre destacando o respeito à natureza, visando a sustentabilidade. Conforme Brose (1999, p. 15), 
[...] hoje o fortalecimento e desenvolvimento da Agricultura Familiar é um dos mais importantes, simples e eficazes instrumentos de geração de emprego e renda, e que constitui a base para um desenvolvimento rural sustentável que reduza a pressão sobre os serviços e infra-estrutura nos centros urbanos.

Nalini (2001) escreve que preservação e progresso não são ideais incompatíveis. Se tivermos em mente a ideia que somos um todo, é possível crescer em consonância com o mundo, respeitando o espaço de cada ser, cooperando uns com os outros.

É preciso reconhecer que, potencialmente, todo sujeito é não apenas ator, mas autor capaz de cognição/escolha/decisão. A sociedade não está entregue somente, sequer principalmente, a determinismos materiais; ela é um mecanismo de confronto/cooperação entre indivíduos sujeitos, entre os "nós" e os "eu" (MORIN, 2003 p. 127).

A proposta do Projeto Rede Viva Charqueadas incluiu técnicas de plantio que não agridem a terra, pelo contrário, possuem capacidade de regeneração da mesma como, por exemplo, o controle biológico das pragas e corretivos orgânicos, ao invés do uso de agrotóxicos pesados. Como se sabe, durante a Revolução Verde predominou a utilização de tecnologias intensivas e insumos, além de ter havido um aprofundamento na desigualdade social no campo, já que predominava a centralização dos ganhos, sem falar na criseecológica causada pelo desmatamento contínuo e intensa degradação:

\begin{abstract}
A partir dos anos 60, vários países latino-americanos engajaram-se na implantação da auto-intitulada Revolução Verde, um ideário produtivo proposto e implementado nos países centrais após o término da Segunda Guerra Mundial, cuja meta era o aumento da produção e da produtividade das atividades agropecuárias, assentando-se, para tanto, no uso intensivo de insumos químicos, variedades geneticamente melhoradas de alto rendimento, expansão dos sistemas de irrigação e, também, na intensa mecanização das ações produtivas - em síntese, uma cadeia articulada de processos e atividades que logo passaria a ser conhecida como o "pacote tecnológico" da agricultura contemporânea (ALTIERI, 1998, p. 7).
\end{abstract}

Para mudar esse paradigma herdado pelo período pós-guerra, a agroecologia propõe as técnicas que sugerem ampliar a biodiversidade, sem ficar dependente do monopólio do mercado das sementes. Propõe também regular o solo e conservar os recursos hídricos, assegurando uma produção sustentável sem uso de agrotóxicos, enfim, promovendo regeneração, conservação e manejo de forma adequada, além de envolver a comunidade, valorizando o saber de cada um, promovendo uma produção e um consumo solidário e responsável. Como destacou Boff (2011) o consumo precisa der solidário, justo e equitativo, além de responsável. Portanto, superar o individualismo, consumir o necessário e compartilhar é fundamental. 


\title{
CRITÉRIOS DE SUSTENTABILIDADE E A BUSCA DE RESULTADOS
}

Os objetivos e diretrizes para elaboração do projeto Rede Viva Charqueadas, como já discutimos, foram baseados na realidade local, através de ações e atividades envolvidas pelos processos educativos ambientais:

\begin{abstract}
Entendem-se por educação ambiental os processos por meio dos quais o indivíduo e a coletividade constroem valores sociais, conhecimentos, habilidades, atitudes e competências voltadas para a conservação do meio ambiente, bem de uso comum do povo, essencial à sadia qualidade de vida e sua sustentabilidade. (BRASIL, 1999, s/p)
\end{abstract}

Neste sentido, o projeto foi elaborado com base em questões sociais e ambientais, o qual inclui aspectos de diversas áreas, como a participação dos envolvidos, fortalecimento da Agricultura Familiar, a gestão dos recursos naturais, a gestão dos recursos financeiros e em as ações para garantir os recursos complementares de cada subprojeto, como, por exemplo, a necessidade de capacitar os participantes de cada subgrupo.

No caso do subprojeto do arroz, conforme Bassi (2008, p. 10), era necessário reduzir ao máximo as externalidades negativas da atividade, adotando estratégias de armazenagem da água utilizada e adequando o sistema para deposição de sedimentos, caso esses sigam para a rede hídrica, e para reuso caso se mantenha em circuito fechado.

O interesse imediato foi iniciar o processo de plantio de arroz agroecológico, eliminando o uso de agrotóxicos, adotando práticas sustentáveis e biodinâmicas no intuito de buscar o equilíbrio do solo, sem uso de insumos prejudiciais à natureza, e cada subgrupo buscando alternativas para cumprir seu papel de sujeito ecológico: "O chão que situa e torna possível o sujeito ecológico é, sem dúvida, a constituição do ambiental enquanto um campo de relações sociais que, como vimos, toma parte entre as tentativas de ressignificar os agenciamentos da experiência individual e coletiva" (CARVALHO, 2004, p. 18).

Outra ação necessária para o subprojeto do arroz era a certificação técnica do produto, a fim de garantir ao consumidor a compra de um produto agroecológico e, após o plantio nesse sistema, iniciar a busca de parceiros para realizar as análises e avalizar a legitimidade do produto, uma forma também de testar as ações do subgrupo em todas as etapas do processo. O encaminhamento do licenciamento ambiental para fins de comercialização, bem como os contatos com as Secretarias Municipais e FEPAM Fundação Estadual de Proteção Ambiental -, também foram apontadas como prioridade, para haver legalidade em todos os âmbitos do subprojeto. 
No subgrupo do leite, era imprescindível garantir o preparo técnico dos produtores, capacitá-los para o processamento do leite. Chegou-se à conclusão que, para isso, era necessário a construção de uma agroindústria com a proposta de centralizar a matériaprima e, então, diversificar a produção dos alimentos oriundos do leite. O referido subgrupo deveria ter a responsabilidade de gestão de produção e financeira, com enfoque participativo e produtivo, fortalecendo a independência e o poder de decisão do grupo, bem como o de definir estratégias para conquistar espaço no mercado local.

Ainda havia a preocupação com o destino dos dejetos, que poderiam causar danos à saúde e ocasionar grande impacto ambiental, pois um grande volume de dejetos acumulados em pequeno local ocasiona a formulação de gases nocivos, sem contar os odores. A proposta para resolver esse problema seria a construção de uma bioesterqueira em ferro e cimento, visando o tratamento dos dejetos e resolvendo de forma prática um problema grave.

Entende-se que para chegar ao resultado desejável no que diz respeito à sustentabilidade é necessário uma longa caminhada, pois o processo de transformação deve ser permanente, sabe-se que não é de uma hora para outra que mudamos os hábitos, no geral somos capazes de reproduzir ações de nosso aprendizado de forma inconsciente, mesmo sem nos dar conta que estamos causando algum prejuízo ao próximo ou à natureza. Mesmo que exista uma consciência de certo ou errado, é necessário processá-la de forma interna, ou seja, refletir profundamente sobre nossos atos a fim de entender que somos parte do mundo e reeducar nossas práticas, para que nossas atitudes sejam construtivas e não destrutivas. Conforme Junges (2001, p. 8), “[...] deve acontecer uma conversão ecológica pela qual o ser humano deixe de se autocompreender como indivíduo separado, para se ver como parte de um conjunto de inter-relações naturais e sociais".

Com a ideia de preservação, o Banco de Sementes, também um objetivo do projeto, veio com uma proposta de caráter inovador, a fim de preservar a biodiversidade das sementes. Na medida em que as pessoas mantém suas próprias sementes não ficam dependentes dos fornecedores do mercado e livres também das sementes geneticamente modificadas.

O mercado busca ganhos. Algumas empresas mundiais (cinco ao todo) produzem sementes transgênicas que vão lentamente substituindo as naturais (erosão genética das sementes ceroulas). Mas acabam monopolizando o mercado de sementes (uma delas controla $90 \%$ ), tornando os produtores econômica e tecnologicamente dependentes. (BOFF, 2006a, p. 35-36). 
Essa proposta tende a difundir as técnicas adequadas para dinamizar as atividades da propriedade, abastecendo as hortas como critério de sustentabilidade, propondo melhor qualidade de vida e complementação da renda.

Pensando ainda em complementação de renda, alguns possíveis beneficiários criavam abelhas para produção de mel, em pequena escala, para o consumo da família e alguma comercialização. Identificando essa ação como um potencial de produção e geração de renda, sugeriu-se a criação do subgrupo do mel. A busca de resultados dependia da capacitação dos produtores, o mel que é considerado uma rica fonte de alimentos deve ser produzido em local livre de agrotóxicos para não correr o risco de contaminação. Para que haja maior produção de mel, é necessário o manejo correto. Existem inúmeros alimentos que podem ser produzidos a partir do mel, bem como é possível explorar a cera e o própolis. Entretanto, a construção de uma agroindústria seria indispensável, na qual os produtores pudessem se organizar como associação e, da matéria prima ao processamento dos produtos, traçar metas de produção, gestão e organização.

Além de atender o mercado local, um dos grandes objetivos era incluir o mel na merenda escolar. A questão vai muito além da comercialização, estamos falando de um conjunto de ações que dá abertura para sair da individualidade para o coletivo, é uma transcendência na busca de novos olhares, novas possibilidades. Boff (2000b, p. 28), afirma que "[...] nós possuímos essa dimensão de abertura, de romper barreiras, de superar interditos, de ir para além de todos os limites. É isso que chamamos de transcendência, uma estrutura de base do ser humano".

Segundo Bassi e Ciotta (2008), apenas três propriedades visitadas apresentam um sistema de produção significativo e comercial de hortaliças, identificando a produção de hortifrutigranjeiros como potencial. Pensou-se na capacitação dos beneficiários visando o aprimoramento do processo produtivo com o uso da irrigação como eixo central e tecnologias permaculturais e agroecológicas. Para isso, organizou-se um curso cujo conteúdo programático abrangeu os seguintes temas:

- Construção e montagem das hortas;

- Planejamento do uso da água;

- $\quad$ Processo produtivo focado na permacultura e agroecologia;

- $\quad$ Preparo e consumo de hortaliças.

A proposta da horta agroecológica seria para atender o consumidor local e, para isso, pensou-se na construção de um centro público, onde os agricultores pudessem levar seus produtos e vender na cidade. Assim, esperava-se diversificar a produção das famílias envolvidas, aumentando e gerando renda através de mecanismos de sustentabilidade. 


\section{A PERCEPÇÃO POR PARTE DOS ENVOLVIDOS SOBRE O PROJETO}

Para compreender como os beneficiários percebiam o projeto, foi utilizado a técnica da entrevista, através da qual, por método qualitativo de análise de dados, foi possível entender a repercussão e impactos do projeto entre os partícipes. Com a autorização dos entrevistados, foi utilizado gravador no momento das falas, a fim de capturar um maior grau de espontaneidade e enriquecer o conteúdo da pesquisa.

Durante a investigação verificamos que os participantes consideraram que o processo valoriza a agricultura familiar, incentivando a permanência do agricultor no campo. Também identificamos em algumas falas que a valorização da identidade profissional, pelo projeto, como salientou um apicultor, fortalece sua estima. Ele ressaltou o reconhecimento da importância da sua atividade exercida na Casa do Mel utilizando os equipamentos fornecidos pelo projeto. Ele disse: "Hoje a produção de mel é minha principal fonte de renda e faço o que realmente gosto". Outro produtor, pertencente ao subgrupo do arroz, falou: "Sozinhos não teríamos condições para sistematizar o solo e manter os custeios da lavoura. Hoje é possível contar com a parceria entre os produtores, existe um planejamento para uso coletivo dos equipamentos fornecidos pelo projeto, como por exemplo, o trator".

Sobre a importância dos critérios de sustentabilidade na produção e os impactos do programa para com os envolvidos no projeto, os participantes destacaram a importância da produção do arroz orgânico, já que fazendo "[...] uso correto do solo para o plantio com o objetivo de preservar a natureza, não utilizando adubação química, é possível valorizar o produto".

Um dos produtores de mel diz que aprendeu muito: "As abelhas realizam um papel importante em prol do equilíbrio ambiental, e com o projeto aprendi a produzir sem prejudicar o meio ambiente".

Também ouvimos um produtor destacar que foi a realização de um sonho a produção na modalidade agroecológica: "Plantar de forma agroecológica era um sonho, e o projeto tornou esse sonho realidade. Temos a preocupação em produzir e comercializar produtos saudáveis sem adição de agrotóxicos e o projeto vem para tornar esse sonho realidade".

Questionamos também os produtores sobre as expectativas dos mesmos sobre as próximas etapas do Projeto Rede Viva Charqueadas: "Para as próximas etapas, precisamos investir um pouco mais em equipamentos para utilização no campo, a fim de viabilizar o aumento produtivo e econômico". Também ressaltaram a necessidade de prepararem-se para avançar na produção e buscar variabilidades dos produtos produzidos à base de mel. 
Um dos produtores do subgrupo do arroz planeja executar toda a cadeia de produção no próprio assentamento, pois se considera capaz de plantar de forma agroecológica, embora a secagem, a armazenagem e a industrialização ainda sejam terceirizadas.

Com relação às questões que envolveram a avaliação do projeto, é possível captar as expectativas para o incentivo da Agricultura Familiar com vistas ao desenvolvimento local. Quando falamos em desenvolvimento, entendemos que estamos indo muito além do crescimento econômico, pois o valor significativo é transcendente, é a partida do pensamento individual para o coletivo, novas perspectivas, oportunidades com objetivo de melhor qualidade de vida a todos que participam desse processo.

Brose (1999) afirma que desenvolvimento representa, antes de tudo, acesso às oportunidades, crescimento e realização pessoal. Melhoria da renda é, portanto um elemento fundamental para desenvolvimento humano, mas não o suficiente.

Consideramos o conceito de Carvalho (2004, p. 6) sobre o sujeito ecológico: "[...] um projeto identitário, apoiado em uma matriz de traços e tendências supostamente capazes de traduzir os ideais do campo". Com base nos depoimentos é possível identificar a formação do perfil do sujeito ecológico, o qual busca sua identidade respeitando as vias percorridas baseadas na sustentabilidade.

\section{CONCLUSÃO}

Ao finalizar esse trabalho foi possível avaliar que para a elaboração dos objetivos e as diretrizes do "Projeto Rede Viva", acertou-se na avaliação de que deveríamos mapear a realidade singular de cada família envolvida como, por exemplo, o perfil produtivo, as potencialidades e as fragilidades, as oportunidades e as possibilidades de ameaças e as melhorias dos sistemas já adotadas.

O projeto foi elaborado com objetivo de incluir, preservar, conscientizar, respeitar a natureza e o ser humano e esses critérios dependem da integração e socialização do grupo, fazendo com que juntos desenvolvessem um processo de transformação, sendo capazes de planejar, tomar decisões, superar os desafios, discutir formas organizativas e exercer a coletividade e a solidariedade. Esse processo fará com que cada agricultor avalie sua trajetória, bem como seu importante papel junto à sociedade, na responsabilidade de trabalhar em prol do bem comum.

Ficou claro que o Projeto Rede Viva foi fundamental para incentivar um crescente apoio à conservação e manejo do solo, com base na produção agroecológica, como foi o caso do plantio do arroz e a produção de hortaliças. 
Cabe salientar que o Rede Viva Charqueadas ofereceu suporte técnico e estrutural para que os subprojetos fossem desenvolvidos. Com a construção da agroindústria para a produção do mel e o processamento do leite, foi possível atingir, em parte, uma das metas que propõe a produção sustentável e coletiva, a segurança alimentar e a geração de renda, com base na sustentabilidade dos recursos utilizados, o que percebemos que o processo de produção coletiva é lento e gradual e exige acompanhamento permanente.

O grande desafio do projeto é o processo de mudança de atitude em todos os aspectos, sejam eles do ponto de vista social ou ambiental. Sabemos que esse processo não acontece de uma hora para outra, pois é fruto de um exercício contínuo. O projeto propicia um cenário ideal para formação de um novo pensamento e novas ações em contribuição para a construção de um mundo mais sustentável e como acompanhar a evolução com atitudes saudáveis.

Com os resultados positivos e perceptíveis através das ações do Projeto Rede Viva Charqueadas junto aos produtores, vimos a possibilidade de mobilizar a comunidade para as questões ecológicas como um todo, chamando a atenção para a forma de manejo do solo e produção de alimentos dos grupos associativos, valorizando as relações e o meio ambiente, deixando de lado práticas extrativistas, e formando uma concepção de cuidado com os bens naturais, os quais sabemos que são finitos e, também, com as questões sociais.

Mediante os desafios da agricultura, o empobrecimento do solo, as questões climáticas e o crescimento do agronegócio, percebe-se que o Projeto Rede Viva Charqueadas trouxe incentivo aos produtores, pois os mesmos demonstram interesse em dar continuidade no trabalho que vem sendo realizado. Com as conquistas realizadas até aqui e com as próximas etapas que o projeto prevê, será possível a consolidação de toda a cadeia produtiva local e também o resgate da valorização profissional dos envolvidos. Isso tudo repercutindo na melhoria de qualidade de vida das pessoas, por estarem produzindo e consumindo alimentos saudáveis e fazendo o que realmente gostam.

O processo de produção de alimentos saudáveis passa a ter um significado muito maior, tanto para o produtor, quanto para o consumidor, que ávido de informações começa a julgar a qualidade dos alimentos a partir de aspectos relacionados às formas de produção, à mão-de-obra e ao respeito ao Meio Ambiente e a Segurança Alimentar em sua forma plena.

A Segurança Alimentar é o eixo básico, no contexto que enfoca a valorização da alimentação para a promoção do desenvolvimento da igualdade social. Os fatores imprescindíveis para a segurança alimentar são: a disponibilidade de alimentos, o acesso e a utilização dos mesmos. 
A implementação de agroindústrias locais representa agregação de valores, a diversificação e fortalecimento dos sistemas produtivos, a saúde pública que, juntos, buscam a verdadeira sustentabilidade local.

Percebe-se que os beneficiários passaram a serem multiplicadores de informações e, através do seu exemplo, estão incentivando mais agricultores a aderirem às práticas sustentáveis, o que reforça a ideia que o processo de conscientização ecológica faz parte de uma caminhada podendo, através das práticas e ações, sensibilizar as pessoas para a construção do desenvolvimento a favor da natureza.

\section{REFERÊNCIAS}

ALTIERI, M. Agroecologia: a dinâmica produtiva da agricultura sustentável. Porto Alegre: UFRGS, 1998.

ASSAD, M. L. L.; ALMEIDA, J. Agricultura e sustentabilidade contexto, desafios e cenários. Ciência \& Ambiente, Santa Maria, n. 29, p. 15-30, 2004. Disponível em: <http://www.ufrgs.br/pgdr/ arquivos/427.pdf> Acesso em: 21 nov. 2016.

BASSI, L. Projeto Rede Viva Charqueadas. Relatório de atividades (produto 1). Coordenador Pedagógico. [S. I.: s. n], 2008.

BASSI, L.; CIOTTA, A. Diagnóstico da situação socioeconômica e ambiental e dos indicadores de impacto das propriedades participantes do projeto Rede Viva Charqueadas. [S.I: s.n.], 2008.

BOFF, L. Consumo solidário e responsável. Entrevista concedida a Equipe Akatu. 2011. Disponível em: <http://www.akatu.org.br/Temas/Consumo-Consciente/Posts/Consumosolidario-e-responsavel>. Acesso em: 5 maio 2011.

Comer e beber juntos e viver em paz. Petrópolis: Vozes, 2006a. v. 3.

. Virtudes para um outro mundo possível: convivência, respeito e tolerância. Petrópolis: Vozes, 2006b. v. 2. 2000a.

Saber cuidar: ética do humano: compaixão pela terra. 6. ed. Petrópolis: Vozes,

Tempo de transcendência: o ser humano como um projeto infinito. 2. ed. Rio de Janeiro: Sextante, 2000b.

BRASIL. Lei n. 9.795, de 27 de abril de 1999. Dispõe sobre a educação ambiental, institui a Política Nacional de Educação Ambiental e dá outras providências. Disponível em: $\leq$ http://www.planalto.gov.br/ccivil 03/leis/L9795.htm>. Acesso em: 5 mar. 2017.

BROSE, M. Agricultura familiar, desenvolvimento local e políticas públicas. Santa Cruz do Sul: EDUNISC, 1999.

CAPORAL, F. R.; COSTABEBER, J. A. Agroecologia e desenvolvimento sustentável: perspectivas para uma nova extensão rural. Porto Alegre: EMATER/RS, 2001.

CAPRA, F. A teia da vida. São Paulo: Cultrix, 1996. 
CARVALHO, I. C. M. Ambientalismo e juventude: o sujeito ecológico e o horizonte da ação política contemporânea. In: NOVAES, R.; VANNUCHI, P. (Org.). Juventude e sociedade: trabalho, educação, cultura e participação. São Paulo: Fundação Perseu Abramo; Instituto da Cidadania, 2004. Pp. 01 - 22.

GADOTTI, M. Ecopedagogia, pedagogia da terra, pedagogia da sustentabilidade, educação ambiental e educação para a cidadania planetária: conceitos e expressões diferentes e interconectados por um projeto comum. 2009. Disponível em:

$<$ http://siteantigo.paulofreire.org/pub/Crpf/CrpfAcervo000137/Legado_Artigos_Ecopedagogia _Pedagogia_da_Terra_Moacir_Gadotti.pdf>. Acesso em: 5 mar. $201 \overline{7}$.

IBGE. Cidades. Charqueadas. 2012. Disponível em: < https://cidades.ibge.gov.br/brasil/rs/ charqueadas/panorama> Acesso em: 5 de março de 2017.

JUNGES, J. R. Ecologia e criação. São Paulo: Loyola, 2001.

LEFF, E. Epistemologia ambiental. São Paulo: Cortez, 2002.

MORIN, E. A cabeça bem feita: repensar a reforma, reformar o pensamento. Tradução de Eloá Jacobina. 8. ed. Rio de Janeiro: Bertrand Brasil, 2003.

NALINI, J. R. Ética ambiental. Campinas: Millennium, 2001.

PORTAL BRASIL. ONU reforça a importância da agricultura familiar. 2014. Disponível em: < http://www.brasil.gov.br/economia-e-emprego/2014/10/onu-reforca-a-importancia-daagricultura-familiar>. Acesso em: 5 jul. 2017.

RIBEIRO, I. C. Educação para a vida: uma experiência metodológica. 2003. 299 f. Tese (Doutorado em Ciências Biológicas) - Universidade Federal de São Carlos, São Carlos, 2003.

SOUZA, M. M. O. A utilização de metodologia de diagnóstico e planejamento participativo em Assentamentos Rurais: o Diagnóstico Rural/Rápido Participativo (DRP). Em Extensão, Uberlândia, v. 8, n. 1, p. 34-47, 2009.

TEIXEIRA, I. Análise dos processos de diversificação produtiva, social e organizacional no Assentamento Trinta de Maio, Charqueadas/RS. 2008. Dissertação (Pós-Graduação em Desenvolvimento Rural) - Faculdade de Ciências Econômicas, Universidade Federal do Rio Grande do Sul, Porto Alegre.

Recebido: setembro de 2016. Aceito: outubro de 2017. 